\title{
Banish waste from civil engineering operations applying lean thinking
}

\begin{abstract}
The paper uses Lean Thinking frame work together with survey data derived on waste. Data indicates that civil engineering operations in general and construction in particular are the most waste intensive operations comparing other sectors. Lean principles were first applied to manufacturing sectors where direct waste generation by weight is the least. Therefore objective of this paper is to answer the diversified problems related to different type of waste and impact on economy of the specific sector. Original concept of such waste measured in tons may not cover the essence of waste in totality because it only describes visible waste. During past studies researchers argued that anything more than minimum materials, equipment, manpower, time required for the product or service would amount to waste. Inclusion of vast scope of civil engineering operations in this exploratory review to banish waste may apparently appear odd. However, we researchers aim to examine the truth in the claim on lean thinking as the single most powerful tool available for creating value while eliminating waste, in any organization, in any industry and in any country.
\end{abstract}

Volume 3 Issue 4 - 2017

\author{
Suresh Sharma,' Pankaj J Gandhi \\ 'Pursuing Ph.D (Management- TQM), Himalayan University, India \\ ${ }^{2} \mathrm{Ph} . \mathrm{D}$ Guide, Visiting Faculty at VNSGU- Surat, India
}

\begin{abstract}
Correspondence: Suresh Sharma, Pursuing Ph.D (Management- TQM), Himalayan University, India, Tel 9I-997-406-264-I,Email suresh_sharmas@rediffmail.com
\end{abstract}

Received: September 28, 2017| Published: November 07, 2017

Keywords: waste elimination, lean thinking, lean construction, passive waste, active waste, value stream

Abbreviations: PERT, program evaluation review technique; CPM, critical path method; TPS, toyota production system; TT, takt time; SOP, standard operating procedure; CAD, computer aided design; JIT, just-in-time

\section{Introduction}

Construction management, one of the disciplines of civil engineering suffers often with problems like delay, cost, and time overrun. Past studies reveal that the above problems are not caused only by physical or material waste. In fact, Koskela ${ }^{1}$ found evidence of waste and value loss due to; flaws in the management system at building sites, non productive time, poor material management, inferior quality of work and safety issues. ${ }^{1}$ Therefore objective is also to; examine if the waste can be identified, classified and quantified in absolute measuring units. Secondly, find methods to banish or reduce waste from other disciplines of civil engineering like: structural engineering, water resource engineering, transport system engineering, ocean engineering besides construction technology and management. The review includes waste generated due to errors in practices of civil engineering at the stage of PERT/CPM planning, designing, constructing and maintaining infrastructure. Many neglected infrastructures such as roads, rail tracks, bridges, dams, irrigation projects, also are within scope of review. Some civil engineering activities like land surveying and land development are kept beyond the present scope of study. However, subject for further research and review will include; more complex deep piling and foundation construction, hydraulic engineering, and environmental engineering. Lean management became internationally recognized as one of the most dominating philosophies with the stunning success of Toyota Production System (TPS). The heart of TPS is eliminating waste and the concept can be applied to any process in industrial or service sector. Jeffrey ${ }^{2}$ described and advocated an effective method to map the activities that added value to the product, eliminating non-value adding activities called 'muda' in Japanese term meaning 'waste'.

The author identified originally seven major types of non-value adding waste in business or manufacturing process. Subsequently one more type was added. The types of waste were termed as: overproduction, waiting, unnecessary transport, over processing, excess inventory, unnecessary movement, defects, and unused employee activity. ${ }^{2}$ The authoritative book on the subject: Lean Thinking, by Womack and Dan Jones, founders of the Lean Enterprise Institute USA and the Lean Enterprise Academy U.K respectively, demonstrates a highly evolved method to banish waste and create wealth in any organization. The authors plead lean as a mindset to achieve a totally waste-free operation with specific focus on customers' requirement. Success comes through continuous improvement in processes involving all the employees. These authors further recommended mangers to think about and act upon three fundamental business issues for success of their organization: purpose, process, and people. All these issues are customer oriented where well planned value-added actions bring growth for the organization as well. Solving of customer's problem meets the organization's own purpose of growth. Process assessment makes sure that every step adds value to the product in the interest of customer. People are important in value stream and therefore it is ensured that they are actively engaged in the process for correctly operating and continually improving.

The authors of Lean Thinking recommend five steps for lean enterprise transformation and the steps are known as Lean Principles.

These principles are termed as;

a. Identify value

b. Map the value stream

c. Create flow 


\section{d. Establish pull and \\ e. Seek perfection in value stream with no waste. ${ }^{3}$}

Many researchers including Ahhilesh ${ }^{4}$ in the past have reviewed and found the method fit for managing an organization to improve the productivity, efficiency, effectiveness, speed and quality of its products and services. ${ }^{4}$ Lean management became popular internationally also as a result of another book Machine that changed the world by the same team of authors having title. The location of soil sampling and preparing process granite residual soil and waste material used I with Don Roose added. The book propagated the fact that the focus of Toyota was on absolute elimination of waste. They termed waste as anything that prevents the value adding flow of material from stage of raw material to finished goods. ${ }^{5}$

\section{Methodology}

Question formation was guided by the objectives of this study to determine whether the civil engineering operations involved in different disciplines including construction industry, structural engineering and others could benefit from the waste elimination method deployed in manufacturing industries based on Lean- Thinking. Specifically, the research team was seeking answer to following questions:

i. Are the waste elimination methods propagated by lean management applicable to civil engineering operations?

ii. Is there any modification in waste elimination method more appropriate to civil engineering?

iii. What is the way forward to banish waste from civil engineering operations?

iv. What hurdles need to be resolved to adopt Lean Thinking way to banish waste?

The approach used was to review and combine the available literature for modulating a method to suit civil engineering operations. Learning from selected case study from the civil engineering field provided opportunity for finding the way forward to banish waste from value stream. The study team reviewed findings of research in civil engineering operations like; construction, steel structural engineering, steel erection process including column and truss, transport system engineering, shipbuilding engineering under ocean engineering, and installation of gas and steam piping. The methodologies were developed firstly for investigating the passive waste at management level on account of wasteful work plan, lack of system, lack of load balancing, and missing optimization effort in crew deployment at work site. Passive waste was analyzed at three different scope levels in waste calculation: operator level, process level, and value stream level. Passive waste measurement was conducted for only selected sample value stream and only periodically where major process change at the work site occurred. A structured observation sheet was used to gather data related to time taken to perform process against 'Takt Time' (T/T) for the selected value stream, where Takt Time is defined as available production time divided by customer demand. ${ }^{6}$ As regards active waste caused by wasteful performance of the actual work, data was collected more frequently in terms of daily unplanned downtime of each process, daily rework time, and daily work-in-process for the selected operation. Active waste metrics was finally compiled taking help of ERP system due to voluminous data. Comparative analysis related to waste in civil operations against manufacturing indicates that; sequence of civil engineering operation is based on discretion where Standard Operating Procedure (SOP) is not documented, material flow is not steady and depends on site location, location for material storage is not fixed, civil construction depends mainly on resources whereas manufacturing depends on machines, civil construction is greatly affected by weather. The other comparison was drawn to find if persons engaged on civil projects are able to identify 8types of lean waste in terms of civil engineering implications. $^{7}$

Recommendation of James $\mathrm{E}^{6}$ was referred and reviewed to formulate relevant examples as under:

i. Overproduction: Overbuilding a portion of project due to overdesign or early start of process than required.

ii. Waiting: Waiting by specific crew to start new activities but previous activity not completed even after lapse of schedule time.

iii. Transport: Wasted effort to transport same building material several times from one place to another.

iv. Extra processing: Waste related to rework due to mistake in design, fabrication, or construction activities.

v. Inventory: Maintaining excess inventory of construction material, equipment or tools.

vi. Motion: Waste related to unnecessary movement of worker or equipment around the construction site.

vii. Defects: Deficiencies in finished product requiring correction.

viii. Unutilized employee creativity: Lack of encouragement to employees for suggesting innovative ideas for improvement.

Observations include both positive and negative situation in the field of civil engineering operations. At progressive industries techniques like; Concurrent Engineering, Last Planner, Daily meetings found in place to improve performance and control different types of waste identified above. These industries also found making best use of ready-mix construction material and sub assembled standard structural components. Such efforts found effective in eliminating waste in the form of excess inventory of construction material, equipment or tools. On the other hand large number of industries found practicing old systems by discretion that too half heartedly. In some other industries Computer Aided Design (CAD) provided efficiency in drawing preparation but structured method of validation like Plan-Do-CheckAct found missing. Therefore un detected design errors caused waste in terms of rework. Positivity in progressive industry found coming from the project manager who acted like customer representative duly empowered by his contractor to communicate effectively and take timely decisions. ${ }^{8}$

\section{Results and discussion}

\section{Way forward}

Having reviewed the status of awareness level among employees and the existing work-culture, a Model was prepared to reduce and eliminate waste from civil engineering operations including construction industries. The Model comprises of training and implementation program simultaneously for waste management as described below 


\section{Contents of training program on waste management}

i. Learning waste management method in different perspectives such as, construction, steel structure fabrication with erection, material handling, environmental and sustainable issues, maintenance and repair services.

ii. Understand waste management through lean technology for eliminating 8 types of waste.

iii. Review ethos like; reduce, recycle, and reuse. ${ }^{9}$

iv. How to launch and institutionalize waste management system to suit the area of operation selected- Roadmap.

v. Understand, identify, quantify, and visualize Passive Wastes.

vi. Understand concepts like Muda, Mura, Muri, Jidoka, JIT etc. for waste prevention, elimination, or reduction. ${ }^{10}$

vii. Case studies and to derive and record specific learning

viii. Learn lean waste metrics to quantify and measure Active Wastes

ix. How to build a response standard of initiation; Plan-Do-checkAct for waste elimination or reduction.

x. How to build continuous improvement culture based on responsive standard.

\section{Implementation program with planned roadmap to} eliminate waste

i. Awareness program for senior executives.

ii. Awareness program for middle management, clubbed with No.1 above, if feasible

iii. Divide facilities into logical areas and identify; raw material and other wastes for proper material accounting. ${ }^{11}$

iv. Formation of steering committee, establishing Goal in measurable terms, and developing a waste management plan integrating different areas.

v. Nominate council members of each area for counseling separately on waste; identification, quantification, and visualization.

vi. Council members training programs to be clubbed with contract personnel for awareness and removal of; Muda (waste), Mura (inconsistency), Muri (strain), Maciej P. ${ }^{5}$

vii. Assessing Passive wastes due to lack of system, wasteful work Organization, lack of load and crew balancing etc James E.

viii. Survey and photography identifying opportunities for making improvements in different areas.

ix. Install a system for measuring Active wastes periodically say, weekly and display on area specific score board.

x. Implement area wise waste elimination or minimization plan using applicable tools like; JIT, Jidoka (automation with human touch), Heijunka (work load balancing), Kaizen, 5- 'S', Root Cause Analysis etc. ${ }^{12}$

xi. Monthly Management Review Meeting to encourage and facilitate continuous waste minimization drive. Declaration and appreciation of the best performer of the month for waste management. xii. Building continuous improvement work culture response standard for sustenance of the waste management system. ${ }^{13}$

\section{Conclusion}

This research concludes with the confirmation on the set objectives of: applicability of lean waste elimination method to civil engineering operations, modulation of these methods to suit the industry, finding a way forward, and to examine and find solution to overcome hurdles associated with this sector. The authors propose a drive to bring better awareness about hidden wastes among the people engaged, through well structured training program. Also a model is proposed to eliminate waste in 12 steps. Future research need to develop a model to eliminate waste from value stream of complex civil engineering operation involving several units together. For example, deep piling and foundation construction in close proximity to sea is a complex operation demanding close co-ordination. Today waste is viewed also from the point of global sustainability. The best way is to avoid generating waste, where feasible. In any case, sample survey data available indicates that in a country five sectors directly account for almost $70 \%$ of total waste generation and the top 2 sectors comprising of mining \& construction alone account for almost $64 \% .{ }^{14}$ Therefore there is significant opportunity to reduce waste in civil engineering operations.

\section{Acknowledgments}

None.

\section{Conflicts of interest}

Authors declare that there is no conflict of interest.

\section{Funding}

None.

\section{References}

1. L Koskela. Application of the New Philosophy to Construction. Technical Report No. 72, CIFF, Standford University, CA, USA; 1992.

2. Jeffrey K Liker. The Toyota Way. TATA McGRAW HIL: India; 2006.

3. James P Womack, Daniel T Jones. Lean Thinking. Simon and Schuster UK; 2003.

4. Akhilesh N Singh. Lean Manufacturing Principles to Practices- 2010 Edition, LB Associates Pvt. Ltd.-India. In: James P Womack, Daniel T Jones, Daniel Roos, Editors. The Machine That Changed The World-2007 edition. Simon and Schuster UK. 2010.

5. Maciej Pienkowski. Waste Measurement Techniques for Lean Companies. International Journal of Lean Thinking. 2014;5(1).

6. James E Diekmann, Mark Krewedl, Joshua Balonick, et al. Application of Lean Manufacturing Principles to Construction. The University of Texas, USA; 2004

7. Remon Fayek Aziz, Sherif Mohamed Hafez. Applying lean thinking in construction and performance improvement. Alexandria Engineering Journal. 2013;52:679-695,

8. Nilya Chhiber. Different Approachesm to Waste: Contrasting Perspectives from India and the USA. Green Economies; 2015.

9. Yes institute. in $>2015 / 11>$ different approaches.

10. Rane T Domingo. Lean Management Principles, India. 2016. 
11. Manufacturing \& Industrial: Waste Minimization. Waste Management Journal of Industrial Ecology.

12. Julie Morgan Leo coci. Recommended practices for the application of leanconstruction methods to building newAustralian LNG capacity engineers Australian WA division. Australia 2012.
13. Waste Elimination/Green NSW.

14. Christa D Jensen, Stuart McInlyre, Max Munday, et al. Who Creates Waste? Different perspectives on waste attribution in a regional economy. 2009. 